\title{
Polyethylene glycol in spinal cord injury repair: a critical review
}

This article was published in the following Dove Press journal: Journal of Experimental Pharmacology

\section{Xi Lu* \\ T Hiran Perera* \\ Alexander B Aria \\ Laura A Smith Callahan}

Department of Neurosurgery, Center for Stem Cells and Regenerative Medicine, University of Texas Health Science Center at Houston, Houston, TX, USA

*These authors contributed equally to this work
Correspondence: Laura A Smith Callahan Department of Neurosurgery, Center for Stem Cells and Regenerative Medicine, University of Texas Health Science Center at Houston, 1825 Pressler Suite 630F, Houston, TX 77030, USA

$\mathrm{Tel}+|7| 3500343 \mid$

Fax +17135002424

Email Laura.A.SmithCallahan@uth.tmc. edu

\begin{abstract}
Polyethylene glycol (PEG) is a synthetic biocompatible polymer with many useful properties for developing therapeutics to treat spinal cord injury. Direct application of PEG as a fusogen to the injury site can repair cell membranes, mitigate oxidative stress, and promote axonal regeneration to restore motor function. PEG can be covalently or noncovalently conjugated to proteins, peptides, and nanoparticles to limit their clearance by the reticuloendothelial system, reduce their immunogenicity, and facilitate crossing the blood-brain barrier. Cross-linking PEG produces hydrogels that can act as delivery vehicles for bioactive molecules including growth factors and cells such as bone marrow stromal cells, which can modulate the inflammatory response and support neural tissue regeneration. PEG hydrogels can be cross-linked in vitro or delivered as an injectable formulation that can gel in situ at the site of injury. Chemical and mechanical properties of PEG hydrogels are tunable and must be optimized for creating the most favorable delivery environment. Peptides mimicking extracellular matrix protein such as laminin and n-cadherin can be incorporated into PEG hydrogels to promote neural differentiation and axonal extensions. Different hydrogel cross-linking densities and stiffness will also affect the differentiation process. PEG hydrogels with a gradient of peptide concentrations or Young's modulus have been developed to systematically study these factors. This review will describe these and other recent advancements of PEG in the field of spinal cord injury in greater detail. Keywords: combinatorial methods, hydrogel, regenerative medicine, nanoparticles, fusogen, drug delivery
\end{abstract}

\section{Introduction}

Spinal cord injury (SCI) disrupts motor, sensory, and autonomic functions that can severely reduce the quality of life for patients. In the USA alone, there is an estimated 54 cases of SCI per million population with $\sim 17,000$ new cases each year. Most incidences of SCI occur because of traumatic incidents such as falls and accidents with men accounting for $\sim 80 \%$ of new SCI cases in the USA. ${ }^{1}$ Unfortunately, no clinical treatment to repair the damage of SCI, such as restoring motor function, exists. Furthermore, the cost of care for patients is significant and exerts a heavy burden on patients, families, and society at large as it can exceed >US\$1 million over the first year. ${ }^{2}$

After SCI, a glial scar forms around the injury area or lesion, which inhibits the growth of new axons and synapses. ${ }^{3}$ Biomaterials offer a variety of strategies for treating SCI by bridging and filling the lesion, delivering cells to replace those that have been lost, or slowly releasing drugs that can mitigate the damage due to inflammation or make the environment more permissible for cell invasion. Reduced lesion formation 
has been reported with biomaterial use. ${ }^{4,5}$ Although a number of biomaterials are being pursued to treat SCI, ${ }^{6}$ this review will highlight the use of polyethylene glycol (PEG), a synthetic material known for its capacity to immediately repair physical damage and reduce local glial scar formation, ${ }^{7}$ and its applications in SCI.

\section{PEG properties and characteristics}

PEG is a relatively inexpensive, water-soluble, and linear polymer that is synthesized by the living anionic ring-opening polymerization of ethylene oxide with molecular weights ranging from 0.4 to $100 \mathrm{kDa}$. End-group modification with different reactive moieties makes it possible for PEG to participate in covalent bonding through a number of chemistries (Figure 1). ${ }^{8-14}$ Attaching PEG through covalent or noncovalent interactions can prolong the circulation of proteins, peptides, and other molecules without compromising their bioactivity. ${ }^{15,16}$ In addition to PEGylation (bioconjugation), PEG can be cross-linked to form porous hydrogels, which can serve as biocompatible matrices that can closely mimic

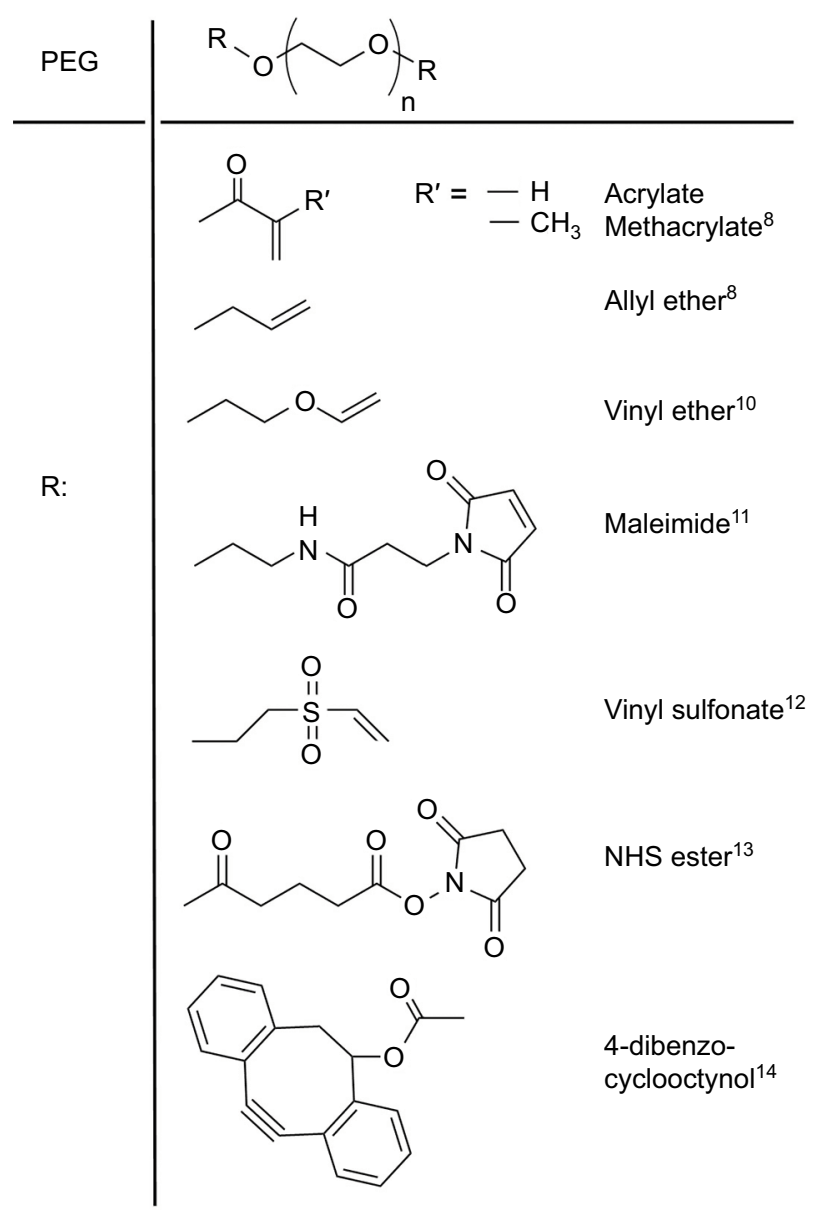

Figure I Reactive moieties that have been used as functional end groups on PEG. Abbreviation: PEG, polyethylene glycol. the extracellular matrix (ECM) found in tissues. ${ }^{17}$ Typically, PEG hydrogels are formed by either photoinitiator- or redox-generated radicals, which initiate chain-growth and step-growth polymerization. The choice of the free radical initiator is important as it affects gelation time, mechanical strength, and the viability of embedded cells. ${ }^{18}$ Photoinitiators, such as Irgacure 2959, have been frequently used for cross-linking PEG, ${ }^{19-21}$ but may be limited in their application in vivo as the light wavelength needed does not easily penetrate tissue. Wilems et al investigated the use of other free radical initiators such as ammonium persulfate (APS)/ tetramethylethylenediamine (TEMED), VA044 (a thermal initiator), and a Fenton chemistry reaction (driven by glucose/ glucose oxidase oxidation/reduction of Fe). ${ }^{8}$ APS/TEMED was determined to be the most viable replacement for Irgacure 2959 of the tested initiators in that study.

Beyond changes due to radical initiator choice, polymer concentration, chain length, and chain configuration (linear, multiarm, grafted, and so on) are known to result in diverse network structures and affect physical and rheologic properties of PEG hydrogels. ${ }^{22,23}$ This makes the hydrogels' mechanical and material properties (such as Young's and shear modulus, mesh size, and so on) easily tailorable. ${ }^{24}$ Copolymers, additives, additional processing (such as electrospinning), and other means can be used to fine-tune matrix properties further, making it applicable to not only SCI but also for other tissue repair. ${ }^{25,26}$

\section{Systematic optimization of PEG systems}

Although various mechanical and physical properties of PEG systems must be optimized to maximize the survival and function of encapsulated cells and promote interaction with the host environment, let us first consider the optimization of the general biochemical environment. The injury environment contains a host of nonpermissive molecules (e.g., chondroitin sulfate proteoglycan or CSPG, Nogo-A, and myelin-associated glycoproteins), which can inhibit axonal growth, and also permissive factors (e.g., laminin and tenascin) that promote axon growth and hence are targets for SCI therapeutics. CSPG is particularly important as it is a key component of the glial scar that forms after SCI. PEG does not prevent the formation of the glial scar but can reduce it. ${ }^{27}$ Glycosaminoglycan (GAG) chains on CSPGs can serve as guidance cues during development but will block axonal growth after SCI. ${ }^{3}$ Traditionally, it has been thought that enzymatic digestion of the chondroitin sulfate GAG chains with enzymes such as chondroitinase $\mathrm{ABC}$ (chABC) may promote regeneration. ${ }^{28}$ However, the instability of chABC 
has limited its use despite efforts to stabilize it. ${ }^{29,30}$ Another strategy for limiting the role of CSPG could be to neutralize specific CSPG sugar epitopes that are responsible for the inhibitory effects of CSPG. ${ }^{31}$ Comparatively, there has been much more effort to engineer and optimize systems for delivering growth-permissive substrates.

Peptides are short sequences of amino acids designed to mimic the biologic function of various growth-promoting molecules such as ECM proteins and neurotrophic growth factors, ${ }^{32,33}$ but are easier to embed because of their smaller size that allows for better dispersion through the threedimensional (3D) material and are more easily tethered with the right regio- and chemoselectivity. Serotonergic innervation, ${ }^{34}$ locomotor recovery, ${ }^{35,36}$ and neural progenitor cell survival and integration ${ }^{37,38}$ have been improved by application of peptides. Peptides can be incorporated into PEG for delivery to the SCI lesion (Figure 2A). ${ }^{20,39}$ In addition, a variety of peptide-conjugated PEG hydrogels have been created and used for studying neural differentiation in vitro. RGD-tenascin-conjugated PEG hydrogels promoted the survival and differentiation of neural stem cells. ${ }^{40}$ An amino acid sequence based on IKVAV, a peptide with similar biologic effect as laminin-1, ${ }^{41,42}$ was incorporated at $10 \mu \mathrm{M}$ concentrations into a PEG tetra-acrylate hydrogel to support growth and differentiation of human neural stem cells. ${ }^{43}$ IKVAV also influences growth cone movement. ${ }^{44}$

ECM proteins that peptides, like IKVAV, mimic play critical roles in supporting axonal regeneration into the injury area. ${ }^{45}$ Without a simple and systematic method, the optimization process can be tedious and expensive for parameters, such as peptide concentration, that affect the success of regenerative medicine approaches for SCI. One can use a continuous-gradient approach to see how changes in the matrix properties will affect the cell behavior. ${ }^{46}$ Using a system of syringe pumps (Figure 2B), Lim et al were able to quickly fabricate a linear gradient of an $\mathrm{N}$-cadherin peptide, HAVDI, embedded within a PEG hydrogel and apply it to studying the survival and neuronal differentiation of mouse embryonic stem cells (mESCs). ${ }^{47}$ They found that there was a biphasic response in the lengths of the neurite extension and Tuj1 expression. After differentiating for 6 days, cells exhibited significantly higher Tuj 1 expression at both 292 and $467 \mu \mathrm{M}$ compared to other concentrations. This type of cellular response is often not identified with traditional optimization strategies. Increasing the amount of HAVDI further led to greater caspase activation and cellular apoptosis. Using this construct, Lim also explored the effects of HAVDI on the differentiation of neural stem cells derived from human-induced pluripotent stem cells. No biphasic response was seen in terms of neurite extensions with the human cells (Figure 2C). The HAVDI concentration with the highest Tuj1 mRNA expression was $577 \mu \mathrm{M},{ }^{48}$ which indicates a potential shift in optimal peptide concentration between the species. These two studies illustrate the usefulness of a gradient system to identify the optimal peptide concentration for neural differentiation.

Aside from molecular gradients, the dimensionality (2D vs 3D) will most likely affect experimental outcomes because cells will behave differently depending on whether they are embedded within a matrix or simply plated on a $2 \mathrm{D}$ surface. ${ }^{46}$ Using a system of three syringe pumps, Yang et al fabricated a PEG hydrogel with a linear gradient of IKVAV ${ }^{49}$ and once again studied the neural differentiation of mESCs cultured both on top of (2D) or encapsulated within (3D) the gels. The difference in dimensionality led to drastically different peptide concentration requirements for successful neuronal differentiation. In 2D, the optimal amount of IKVAV for mESC's neuronal differentiation and survival was $570 \mu \mathrm{M}$ with lower IKVAV concentrations resulting in decreased cell attachment. Whereas in 3D, $60 \mu \mathrm{M}$ of IKVAV showed greater neuronal marker expression compared to that of higher concentrations (Figure 3A). It is clear from the results of this study that dimensionality is an important consideration when interpreting biologic data and translating the results of in vitro studies to in vivo experiments. The $2 \mathrm{D}$ environment may not recapitulate all of the signaling found in a $3 \mathrm{D}$ system; gradient hydrogels provide a facile way for studying the response of cells to changing extrinsic factors in an environment that may better emulate that which is found in vivo.

Mechanical properties such as stiffness and crosslinking density are other important parameters that can be conveniently studied with gradient hydrogels. Mosley et al demonstrated the fabrication of a PEG hydrogel with a continuous linear gradient of Young's moduli and examined how varying the stiffness of a hydrogel can affect neuronal differentiation and neurite extensions of human neural stem cells. ${ }^{50}$ They determined that a Young's modulus of $907 \mathrm{~Pa}$ allowed for the longest axonal extensions (Figure 3B) and MAP2 expression, which closely abide with the Young's modulus of the brain and spinal cord..$^{51}$ Hydrogels with a lower moduli (502 Pa) showed decreased levels of Tuj1 despite other matrix properties such as swelling ratio and mesh size being the same. At higher Young's moduli (2-3 $\mathrm{kPa}$ ), hydrogels demonstrated decreased Tuj1 and MAP2, but higher GFAP expression. Neurons are not the only cell types affected by matrix stiffness. A study compared the 
A



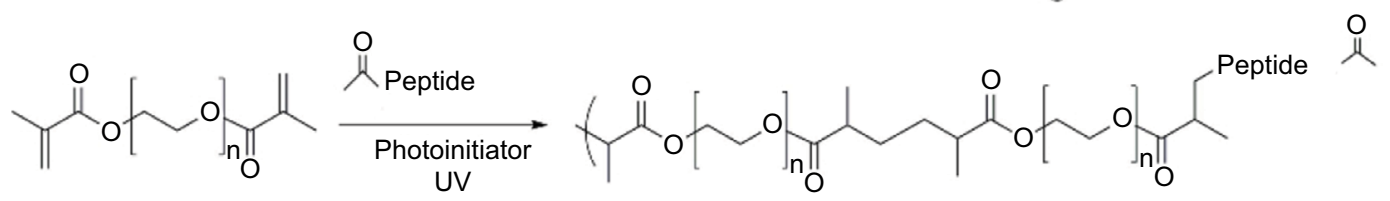

B

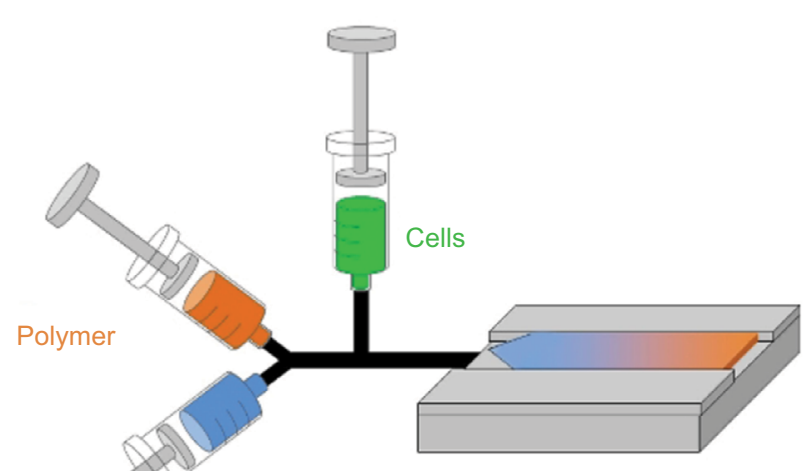

Polymer + peptide

C
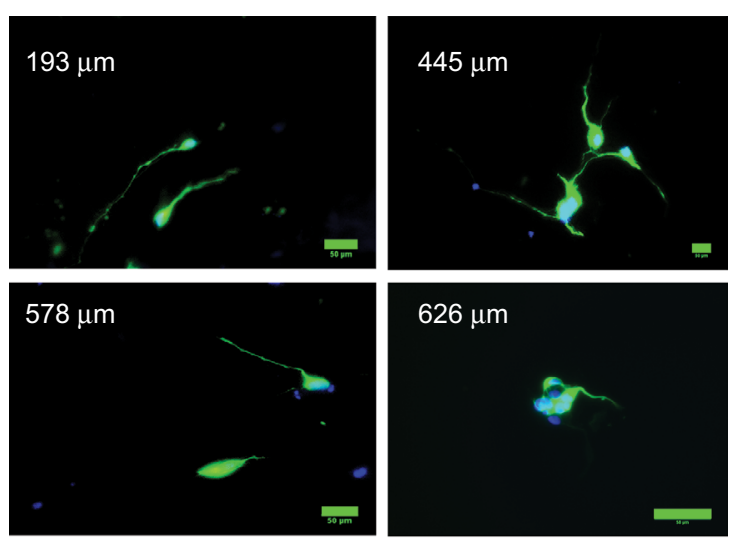

$626 \mu \mathrm{m}$
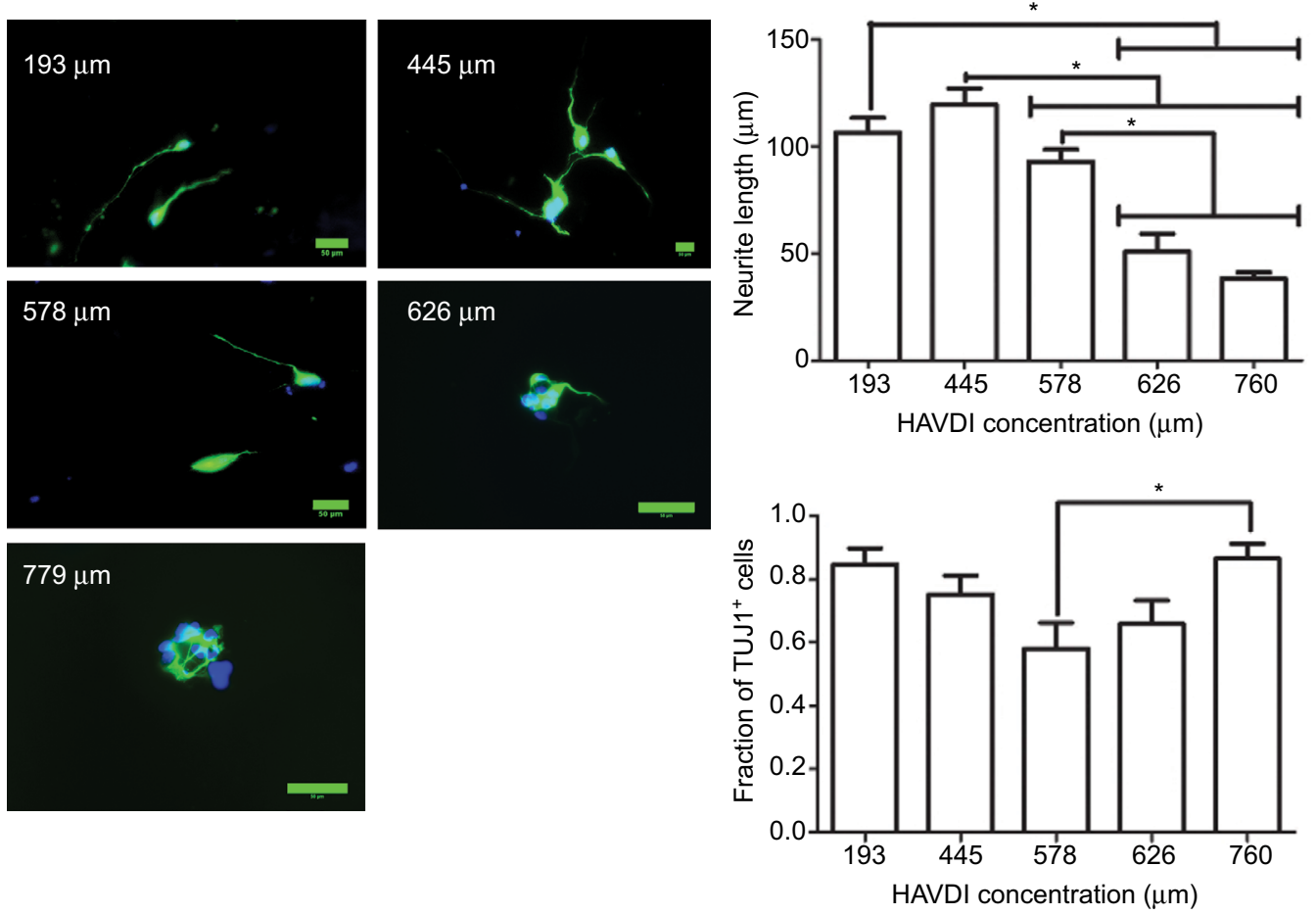

Figure 2 (A) Schematic for tethering peptides to PEG dimethacrylate gels. (B) Diagram of a syringe pump system used for embedding a linear gradient of peptide within a hydrogel. For two-dimensional cultures, only two polymer (with/without peptide) syringes are needed to generate the hydrogel. For three-dimensional cultures, the cell syringe is added and pumped along with the other two syringes. There is no disruption to the peptide gradient with the third syringe. (C) Effect of different HAVDI peptide concentrations on Tujl expression and neurite extension from human neural stem cells. $* P$-value $<0.05$.

Note: Adapted with permission from Lim HJ, Khan Z, Wilems TS, et al. Human induced pluripotent stem cell derived neural stem cell survival and neural differentiation on polyethylene glycol dimethacrylate hydrogels containing a continuous concentration gradient of N-Cadherin derived peptide His-Ala-Val-Asp-lle. ACS Biomater Sci Eng. 2017;3(5):776-78I. Copyright 20I7. American Chemical Society. ${ }^{48}$

Abbreviation: PEG, polyethylene glycol. 
A

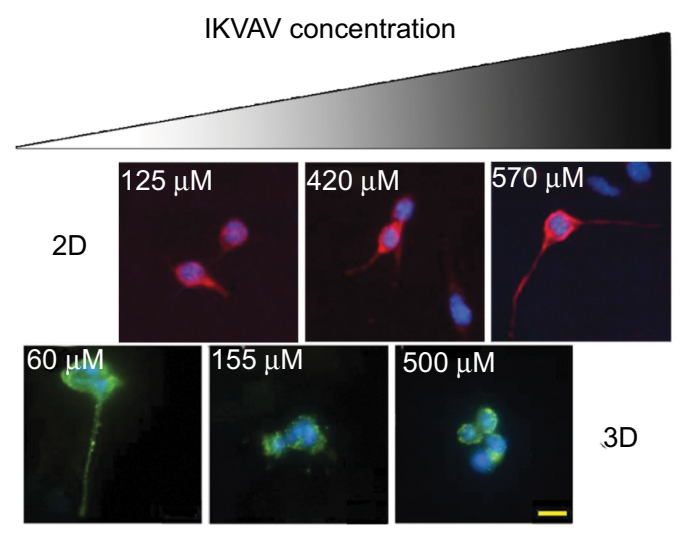

B

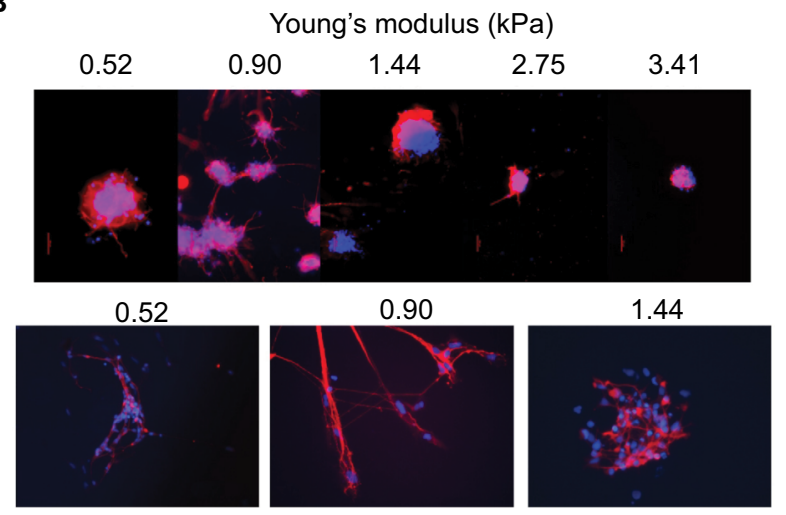

Figure 3 (A) Effect of IKVAV concentration on axon length of mouse embryonic stem cells (Tuj I/DAPI staining) changes depending on whether the cells are cultured in a $2 \mathrm{D}$ or a $3 \mathrm{D}$ setting. A much lower concentration of IKVAV is necessary for inducing differentiation in $3 \mathrm{D}$ culture than that in $2 \mathrm{D}$ culture. (B) Effect of different Young's modulus on axon length (Tuj I/DAPI staining) of human-induced pluripotent stem cells. Second row is simply higher-magnification images of the axons. Scale bar indicates $20 \mu \mathrm{m}$.

Notes: (A) Adapted from Acta Biomater, 2I, Yang YH, Khan Z, Ma C, Lim HJ, Smith Callahan LA, Optimization of adhesive conditions for neural differentiation of murine embryonic stem cells using hydrogels functionalized with continuous lle-LysVal-Ala-Val concentration gradients, 55-62, Copyright 2015, with permission from Elsevier. ${ }^{49}$ (B) Adapted from Mosley MC, Lim HJ, Chen J, et al. Neurite extension and neuronal differentiation of human induced pluripotent stem cell derived neural stem cells on polyethylene glycol hydrogels containing a continuous Young's Modulus gradient. J Biomed Mater Res A. 2017;105(3):824-833. With permission from John Wiley and Sons. ${ }^{50}$

Abbreviations: 3D, three-dimensional; DAPI, 4',6-diamidino-2-phenylindole.

effects of storage modulus and cross-linking density on oligodendrocyte progenitor differentiation. Compared to long-chain-length PEG, hydrogels derived from shorterchain-length PEGs possessed a higher cross-linking density that resulted in a stiffer material and led to higher expressions of PDGFR $\alpha .^{52}$ These studies reinforce the importance of modulating mechanical properties to fit the differentiating neural ${ }^{53,54}$ or glial cells $\mathrm{s}^{55,56}$ for treating SCI.

\section{PEG in preclinical models of $\mathrm{SCl}$}

It is long known that the mechanical force of the primary injury leads to an influx of $\mathrm{Ca}^{2+}$ into neurons. ${ }^{57}$ This accumulation of $\mathrm{Ca}^{2+}$ generates free oxidative radicals that have disastrous effects on axons leading to apoptosis and proteases activation..$^{58}$ PEG is a surfactant because of its hydrophilic nature. These properties promote fusion of cell membranes and membrane fluidity. ${ }^{59}$ During the acute phase of SCI, PEG may inhibit nerve fiber degeneration and create a favorable microenvironment for the regeneration of nerve filaments. ${ }^{7}$ The combined actions of sealing cell membranes with PEG and applying an electric field were able to block inward flux of $\mathrm{Ca}^{2+}$ ions and lead to enhanced functional recovery. ${ }^{60}$

PEG can also stimulate angiogenesis, isolate or reduce local glial scar invasion, promote and guide axonal regeneration, and restore synaptic connections with target tissue, hence stimulating injury repair. ${ }^{61}$ PEG hydrogels have high water content and porosity, which make them behave like aqueous solutions at a microscopic scale while being macroscopically solid. This facilitates the uptake and diffusion of molecules and cells. Molecules smaller than hydrogel pores can be released through diffusion, while larger molecules can be released through degradation and swelling. ${ }^{62}$ PEG has a wide range of bioengineering applications ranging from a membrane patch to $3 \mathrm{D}$ scaffolds and drug delivery vehicles. ${ }^{9-13,49,63}$ In this section, we will discuss specific applications of PEG in SCI in greater depth (Table 1).

\section{PEG as a fusogen}

The loss of membrane integrity seriously harms cells because of disruptions in the balance of ions and subsequent release of reactive oxygen species from the mitochondria and threatens to deleteriously affect spinal cord functionality as the damage spread beyond the initial injury site. In SCI, PEG has been shown to act as a fusogen with the ability to repair compromised neuronal membranes. ${ }^{59,64}$ While the exact mechanism of fusing the cell membrane is unclear, it has been

Table I A summary of technologies and methods in which PEG has been used to treat different phases of SCl

\begin{tabular}{ll}
\hline Acute & Subacute and chronic \\
\hline Fusogen* & Pegylated drugs, proteins, and particles* \\
Pegylated drugs, proteins, & Injectable liquid PEG \\
$\begin{array}{l}\text { and particles* } \\
\text { Injectable liquid PEG* }\end{array}$ & ECM protein/peptide-loaded hydrogels \\
& $\begin{array}{l}\text { Stem/progenitor cell delivery }^{+} \\
\text {Microcarrier-loaded hydrogels }\end{array}$ \\
\hline
\end{tabular}

Notes: *Indicates established technology. +Indicates emerging technology.

Abbreviations: ECM, extracellular matrix; PEG, polyethylene glycol; $\mathrm{SCl}$, spinal cord injury. 
hypothesized that either PEG dehydrates the cell membrane and allows lipid elements to resolve into each other or PEG reduces the surface tension and improves the membrane's fluidity so that sealing may occur. ${ }^{65}$

Ren et al performed laminectomy at T-10 in rats and immediately applied either saline or PEG-600 directly to the point of transection in an attempt to refuse the thoracic spinal cord. ${ }^{66}$ The blood-brain barrier (BBB) score of the PEG-treated group steadily improved over a period of 28 days, whereas the saline-treated group did not. Recordings of somatosensory evoked potentials (SSEP) showed recovery of the waveform in PEG-treated animals, whereas the SSEP form did not recover in control animals (Figure 4A). Direct tensor imaging (DTI) showed that this recovery may be partially due to the tissue continuity found in PEG group (Figure 4B). In a recent but still ongoing study, Liu et al applied PEG as a fusogen in an acute complete transection of dog's spinal cord at T-10. ${ }^{67}$ Using a modified BBB score for assessing dog locomotion, the PEG-treated group had a median score of 8 while the negative control group had a score of 3 (scale is $0-15$ with 0 being no hindlimb movement). DTI showed some fiber reconstitution in PEG-treated group along with increased SSEP waveforms compared to no treatment. As of the writing of this review, the study is still incomplete, but it is important to note that this extremely acute injury model is a clean transection, which is quite different from blunt trauma and generates a comparatively less substantial glial scar. Other work has shown that formation of the astrocyte scar may beneficially participate in the regeneration process until the subacute phase and then it becomes prohibitive. ${ }^{68}$ Ren notes that PEG does not prevent the formation of the scar and hypothesizes that axon regrowth through the PEG matrix occurs before the subacute phase and helps to bridge the ends of the severed cords, thus contributing to the restoration of function. ${ }^{66}$ Similarly, Kim conducted cervical laminectomy at C5 in a rat SCI model and then immediately applied PEG-600 or saline. Measurements of motor evoked potential (MEP) found that PEG-treated animals showed an increase in the measurement of MEP's amplitude (mean of 0.081 vs $0.156 \mathrm{mV}$ ) at 1 hour after injury. ${ }^{69}$ While it is not
A
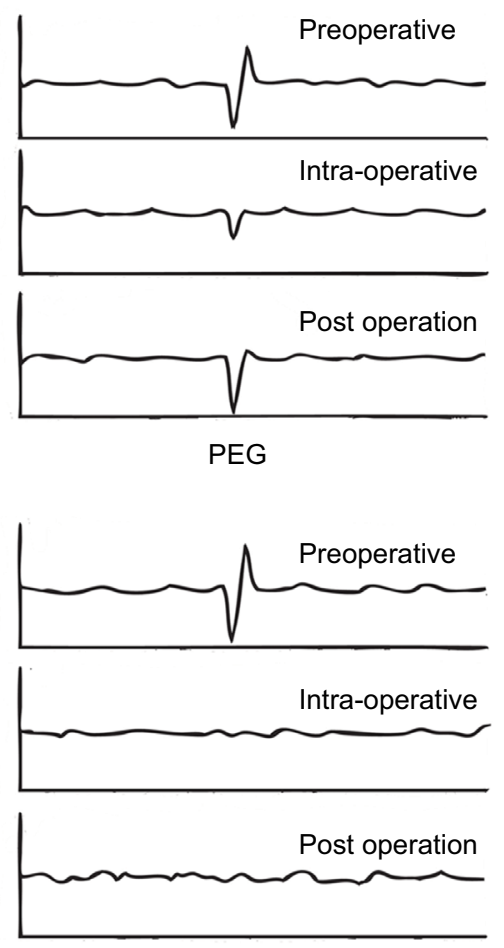

Control
B

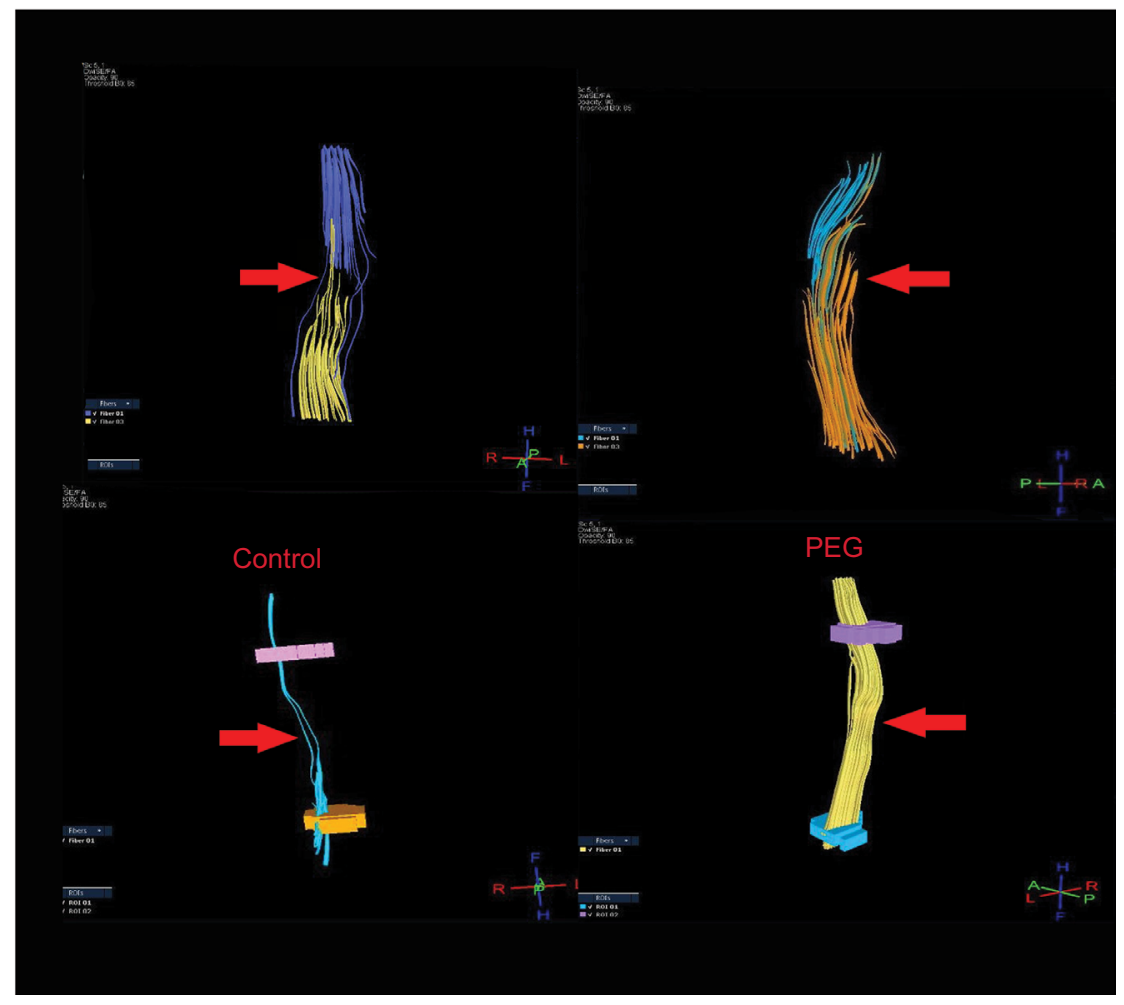

Figure 4 (A) Waveform of somatosensory evoked potentials before and after ( 15 days) spinal cord transection for PEG-treated and negative control groups. PEG treatment elicited some recovery in the shape of the waveform compared to no treatment at all. (B) Diffused tensor imaging of spinal cord transection with/without PEG treatment. PEG treatment group led to greater continuity of nerve fibers compared to no treatment.

Note: For control (left column), arrows indicate the persistence of injury gap. For PEG treatment group (right column) arrows indicate the disappearance of gaps (greater tissue continuity). Adapted from Ren S, Liu Z-H, Wu Q, et al. Polyethylene glycol-induced motor recovery after total spinal transection in rats. CNS Neurosci Ther. 20I7;23(8):680-685. With permission from John Wiley and Sons. ${ }^{66}$

Abbreviation: PEG, polyethylene glycol. 
yet clear how well these results would translate to a clinical setting, they are encouraging and are suggestive of the benefits of early and direct application of PEG to the severed spinal cord in order to mitigate neural damage and promote the regenerative process.

\section{Injectable PEG}

Various PEG formulations have been developed to create injectable platforms that offer the ability to deliver cells or other drugs directly to the site of SCI..$^{70,71}$ One of these has highlighted the potential of using PEG beyond the early phases of SCI. Estrada et al compared the application of PEG-600, matrigel, or alginate to rats in a chronic model ( 5 weeks) of SCI. After either a hemisection or complete transection, the lesion scar was resectioned and treated with the polymers. Matrigel did not elicit any axonal in-growth into the biopolymers, whereas there was no difference between the axonal extensions of the alginate- or resection-only group. PEG-600 group showed the highest axon density within the lesion area and correspondingly had the greatest vascularization (in terms of number of blood vessels and their size) within the graft. Aside from axons, they also identified the presence of Schwann cells, astrocytes, and endothelial cells within the PEG-600 graft with limited number of B- and T-cells and ED-1-positive inflammatory cells. Even though there was some heterogeneity in the BBB score of animals receiving PEG-600, overall, they still performed better than the transection-only group. This work highlights the idea that even in a chronic injury setting, PEG can act as a supportive matrix and promote the infiltration of glial cells such as astrocytes and Schwann cells as well as angiogenesis to promote axonal regrowth and some functional recovery. ${ }^{70}$

Oda et al studied the effects of delivering combinations of PEG and bone marrow-derived mesenchymal stem cells (MSC) in a mouse model of SCI. Female ICR mice underwent T-10 dorsal laminectomy and were then injected with PEG, MSC, or PEG+MSC. Only MSC alone or PEG+MSC showed significant migration of neuronal cells toward the glial scar area (Figure 5). Interestingly, all of the groups showed higher but similar motor function scores compared to the negative control, so PEG and MSC did not have any synergistic effect on functional recovery. ${ }^{72}$

Huang et al investigated PEG infused with magnesium sulfate (AC105) and its impact on reducing excitotoxic glutamate exposure in a rat SCI model. ${ }^{73} \mathrm{As}_{\mathrm{Mg}^{2+}}$ homeostasis is important for a variety of cell functions such as membrane stabilization and energy metabolism, restoring this homeostasis may be beneficial for SCI. After a T9/10 laminectomy, the extracellular $\mathrm{Mg}$ concentration decreased significantly. Single injections of AC105 showed some recovery in the levels of $\mathrm{Mg}$, whereas either delivery of saline or $\mathrm{MgSO}_{4}$ did not. Multiple deliveries of $\mathrm{AC} 105$ raised extracellular $\mathrm{Mg}$ concentration even more. Though not statistically significant, extracellular glutamate levels increased by $20 \%$ after SCI; this elevation was abolished by treatment with $\mathrm{AC} 105$ but not $\mathrm{MgSO}_{4}$. It is yet unclear whether a potential PEG-Mg complex could explain AC105's superior performance over direct $\mathrm{Mg}$ delivery but, nevertheless, as glutamate-N-methylD-aspartate excitotoxicity is a major driver of secondary SCI damage, injectable PEG with Mg or other ions may help to mitigate its damage.

Injectable PEG can also be delivered as a polymer that can cross-link and gel in situ; this offers the advantage of a matrix that can conform geometrically to the defect without requiring a pregelled patient-specific hydrogel or causing additional excision of healthy tissue. After injection, functionalized polymeric scaffolds can support spinal tissue regeneration by promoting revascularization ${ }^{74}$ and encouraging axonal infiltration into the matrix. ${ }^{75}$ Comolli et al had developed a poly(N-isopropylacrylamide)-co-poly(ethylene glycol) injectable platform for SCI, which allowed for the slow release of growth factors such as brain-derived neurotrophic factor (BDNF) and neurotrophin-3 as well as enabling the survival of MSC. ${ }^{76}$ Using this platform as an inspiration, Cai et al developed a shear thinning hydrogel designed to protect the cells from the injection process and slowing down the degradation time after the gel has formed at the injury site. ${ }^{77}$ The ex vivo network is formed between an eight-arm peptide-PEG copolymer that assembles with a recombinant protein and then in situ cross-linking occurs because of the thermal phase transition of a PNIPAM chain conjugated to the PEG copolymer. By increasing the density of the PNIPAM network, it is possible to modulate and slow the degradation rate of the gel, which can then improve cell retention and lower the initial number of cells that must be implanted.

\section{PEG and nanoparticles (NPs)}

PEG can also act as a surface ligand for improving the delivery of NPs in order to treat SCI. The small size of NP offers the advantage of easily crossing cell membranes for targeted drug delivery. ${ }^{78}$ A variety of NP systems have been developed for neural drug delivery applications such as transporting methylprednisolone, ${ }^{79}$ growth factors such as bFGF- $2,{ }^{80}$ and serotonin receptor agonists. ${ }^{81}$ For systemic delivery of NP, commonly encountered obstacles that can 

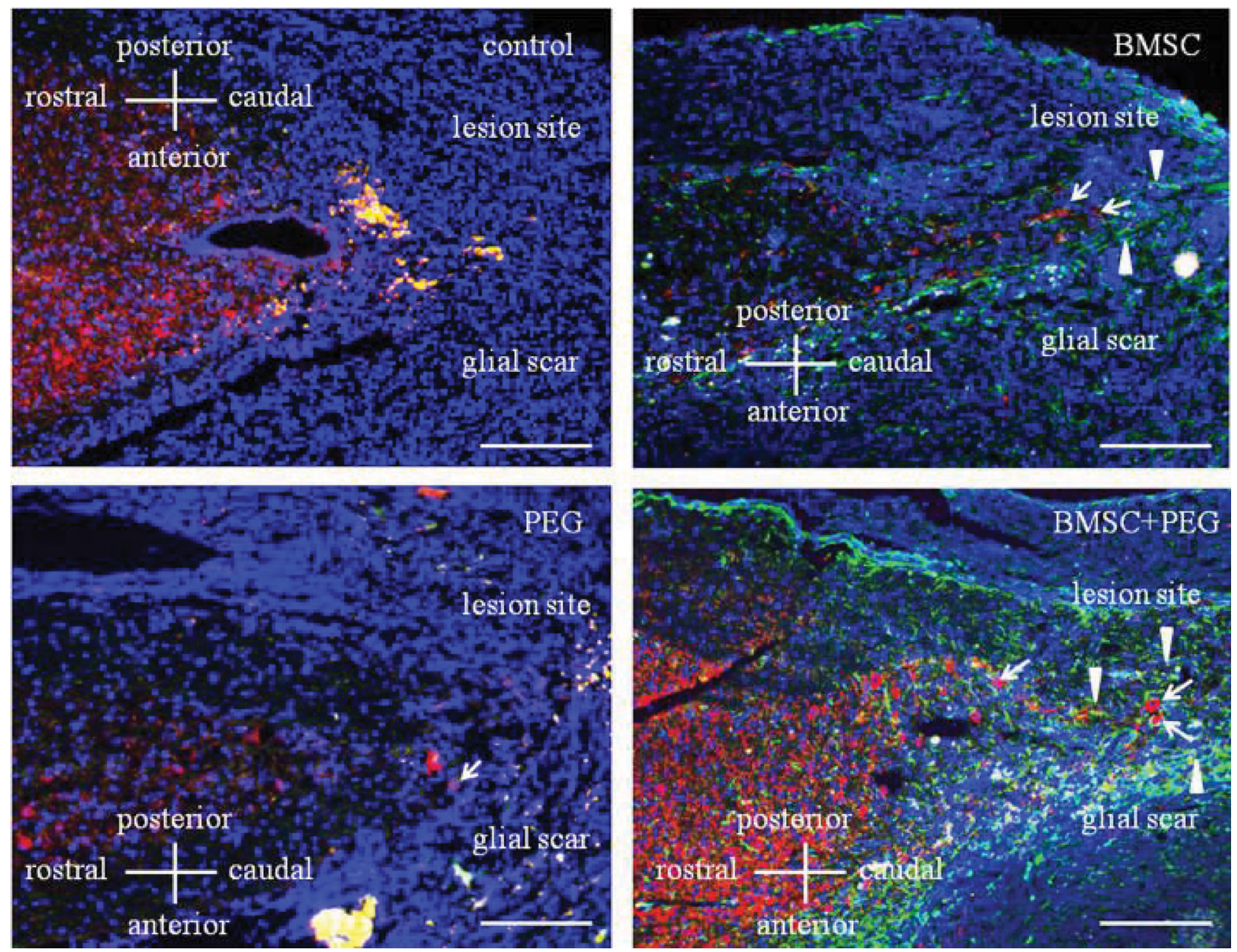

Figure 5 Image of glial fibrillary acidic protein (green), microtubule-associated protein 2 (red), and 4',6-diamidino-2-phenylindole staining of thoracic cord in mice 4 weeks after injury with transplantation of MSC with/without PEG. Compared to all other groups, mice treated with both PEG and MSC showed many neuronal cells migrating toward the glial scar.

Notes: Scale bar indicates $750 \mu \mathrm{m}$. Arrows indicate MAP-2 positive cells. Arrowhead indicates GFAP positive cells. Reproduced with permission of the Japanese Society of Veterinary Science from Oda Y, et al. J Vet Med Sci. 2014;76(3):4I5-421. ${ }^{72}$

Abbreviations: MSC, mesenchymal stem cells; PEG, polyethylene glycol; BMSC, bone marrow derived mesenchymal stem cell.

prevent NP from reaching their target are clearance by the reticuloendothelial system and/or being blocked by the BBB. Covalent/noncovalent attachment of PEG (PEGylation) to NP allows them to have reduced immunogenicity ${ }^{82,83}$ and better penetrate the BBB. ${ }^{84}$

Despite its reputation of being a "stealth" coating material, there have been reports of anti-PEG antibodies present in human and animal models. ${ }^{85-87}$ PEG hydrogels have also been known to stimulate foreign body response. ${ }^{88,89}$ Interestingly, anti-PEG antibodies (ab) have been detected in patients treated with and without PEGylated drugs, perhaps due to the widespread use of PEG in household products including toothpaste and shampoo. ${ }^{90}$ Consequently, the $\alpha$-PEG ab may lead to the accelerated blood clearance of PEGylated therapeutics in the liver and effectively decrease their efficacy. ${ }^{91,92}$
Previously, it was found that PEGylated liposomes stimulated immunoglobulin $\mathrm{M}(\operatorname{IgM})$ ab production in marginal zone (MZ) B cells without any dependence on T-cells. ${ }^{93}$ Subsequently, the anti-PEG IgM ab binding to PEGylated liposomes and their recognition by complement receptors on the surface of the MZ B-cell can lead to transport of the liposomes to spleen follicles. ${ }^{94}$ The exact binding epitope is uncertain but B-cell activation may occur because of identical repeating epitopes. ${ }^{95}$ It may also be that PEG acts as a hapten and only elicits an immune response when conjugated to another molecule. ${ }^{96}$

Papastefanaki et al investigated the use of PEG-functionalized $40 \mathrm{~nm}$ AuNP for treating SCI. ${ }^{97}$ In vitro, the AuNP offered protection against $\mathrm{H}_{2} \mathrm{O}_{2}$-induced toxicity of mouse cerebellar neurons. Using a mouse model of compression SCI, they showed that animals treated with AuNP had higher 
BBB scores as well as other hindlimb improvements such as foot stepping angles and ladder climbing. The PEG-AuNP also decreased the microglia presence at the injury site, which suggests the NP's capacity to attenuate the immune response. Animals with AuNP also showed higher number of motor neuron survival compared to PBS controls along with greater remyelination of existing axonal fibers.

Papa et al studied the effects of surface charge and PEGylation on the uptake of poly methyl(methacrylate) NP by microglia and used this system to deliver antiinflammatory drugs. ${ }^{98}$ Their results showed that positive surface charges increased uptake, whereas PEGylation slowed but did not block uptake of the NP by activated microglia. After uptake, drugs were released through a Fickian diffusion mechanism. In accordance with this result, Jenkins et al studied the effects of PEGylation on magnetic NP and their uptake by major cells within the central nervous system such as microglia, oligodendrocyte precursor cells, astrocyte, and neurons. They found that PEGylation reduces uptake by all of these cells, which then increased the extracellular availability of the NPs. ${ }^{99}$ Therefore, depending on the application, PEGylation must be carefully tuned and modified or otherwise it may produce an undesired result by limiting the amount of NP being delivered to the target.

PEGylation is not the only application of PEG in nanomedicine. Nanomicelles have been derived from triblock monomethyl PEG-poly(l-lactide)-poly(trimethylene carbonate) copolymers. These nanomicelles were loaded with zonisamide that slowly released over a period of 2 weeks. These nanomicelles protected CTX TNA2 cells against $\mathrm{H}_{2} \mathrm{O}_{2}-$ induced toxicity and when cultured with cortical neurons, increased the axon lengths. When used in an in vivo rat SCI model, animals treated with the nanomicelles showed improved BBB scores. ${ }^{100}$ PEG-DSPE micelles formulated with apamin, a small 18-amino-acid peptide known to penetrate the $\mathrm{BBB}$, was used to target micelles to the spinal cord. ${ }^{101}$ Delivery of the micelles that carried curcumin, known to possess antioxidant properties, significantly improved the $\mathrm{BBB}$ score of the animals.

\section{PEG as drug and cell delivery vehicles}

In addition to PEGylation, various PEG-based structures such as micelles and hydrogels have been extensively used as delivery vehicles. The payloads can be either proteins such as growth factors, bioactive peptides, or cells. ${ }^{102}$ Various modifications to confer degradability to PEG hydrogels and incorporation of growth factors/immunomodulatory drugs have been developed for PEG combinatorial tissue engineering strategies. ${ }^{103,104}$ Cholesterol coupled to PEG to create a cholesterol-ortho-nitrobenzyl-PEG complex, which was then used to fuse two distinct liposomal membranes in situ. ${ }^{105}$ This system may be used for intracellular release of liposome-encapsulated drugs. Lampe et al developed that PLGA microspheres loaded with BDNF and glial cell linederived neurotrophic factor (GDNF) can be embedded within degradable PEG hydrogels for a slow release of their cargo. This controlled delivery of neurotrophic factors reduced the microglial response. ${ }^{106}$ Recent work with a layered agarose gel functionalized with PEG, poly(acrylic acid), and BDNF has shown that this construct is capable of controlled release of BDNF over 10 days. In addition to providing chemical signaling, this gel also possesses linear channels to provide physical cues to guide axonal growth. ${ }^{107}$

However, low-molecular-weight PEG may be deleterious to the release of encapsulated proteins. An injectable hybrid NP/hydrogel system was used to study the release of PDGFAA from PLGA NPs that were embedded in a PEG-400 hydrogel. ${ }^{108}$ The addition of PEG-400 lowered the release of detectable PDGF-AA; over half of the encapsulated protein remain unaccounted for after 21 days. As PEG did not affect the release of encapsulated bovine serum albumin, it could have altered the protein stability of PDGF-AA rather than the NP. It is unclear by what mechanism PEG affected the PDGF-AA as the authors did not find any effects of PEG on the release of BDNF. Other studies have noted widely varying results on how PEG-400 affects other neurotrophic factors. ${ }^{109,110}$

Additionally, the stability and availability of encapsulated protein in PEG hydrogels may be affected by the crosslinking reaction. Hammer et al studied the modifications to lysozyme after encapsulation in various PEG gels fabricated from PEG derivatives including PEG5k-maleimide, -acrylamide, -thiol, and -furan. ${ }^{111}$ Depending on both the $\mathrm{pH}$ and type of PEG derivative, multiple PEG chains were attached to lysozyme, which also affected the proportion of free and bound proteins within the gels and may potentially affect the protein's function. The susceptibility of each protein may be affected by the nucleophilicity of the amino acids that may react with $\alpha, \beta$-unsaturated carbonyl compounds in Michaeltype addition reactions. Also, the distribution of the amino acids should be considered as those on the protein surface are more easily available to reaction than those found within the protein core. Precipitation with PEG or $\mathrm{Zn}^{2+},{ }^{112}$ addition of transition metal chelators, ${ }^{113}$ or separating hydrophobic polymerization sites from hydrophilic protein areas have been presented as strategies for preserving protein function. ${ }^{114}$ 
Therefore, continued study of the mechanism underlying this phenomenon is highly warranted.

Cell delivery is a particularly attractive candidate for treating SCI because not only can the cells replace those cells that were lost, they can also secrete a variety of cytokines and growth factors to stimulate native tissue regeneration. These cells may increase cell-cell interaction, adhesion, survival and proliferation, and differentiation. ${ }^{115-117}$ Common cell types for inclusion into PEG-based scaffolds include neural progenitors derived from embryonic or induced pluripotent stem cells or MSC. Neural progenitor cells can differentiate into neurons for restoring connectivity ${ }^{118}$ or glial cells such as Schwann cells to secrete growth factors such as GDNF for promoting axonal regeneration and remyelination. ${ }^{119}$ Human MSC were delivered in a hydrogel PEG/carbomer/agarose with RGD peptide and ECM matrix deposits secreted by MSC. These MSC delivered paracrine factors. The cells survived and proliferated in vivo inside these gels for 9 days. During that time, they modulated the immune response as evidenced by the increased M2 macrophage presence. ${ }^{120} \mathrm{~A}$ rat model with acute SCI was treated with scaffolds of PEG fumarate and Schwann cells to successfully trigger axonal regeneration. ${ }^{121}$ They observed that animals with implanted scaffolds, with or without cells, had similar levels of collagen scarring and cyst formation, and accumulation of CSPG after 8 weeks. However, when animals with scaffold were compared to animals with injury only, these factors were significantly reduced.

\section{Conclusion}

Despite having a simple structure, PEG has a flexibility in processing, which has made it useful in a number of applications for SCI. As we deepen our understanding of cell-material interface and the SCI lesion biology, we expect to see further utilization of PEG in treatment development. Combination treatments that use PEG as both a fusogen and a structural component like a hydrogel matrix will likely be developed. Adoption of high-throughput methods to systematically optimize PEG-based and other experimental treatments will further expedite the transition of PEG from experimental to clinical treatments for SCI. This transition toward greater use of PEG in the clinic is already occurring in other tissues.

\section{Acknowledgments}

The author would like to acknowledge financial support from the following sources: Mission Connect, a TIRR program (014-120), The Staman Ogilvie Fund, William Stamps Farish
Fund, Bentsen Stroke Center, and Vivian L. Smith Department of Neurosurgery.

\section{Disclosure}

The authors report no conflicts of interest in this work.

\section{References}

1. Center NS. Facts and Figures at A Glance. Birmingham, AL: University of Alabama at Birmingham, 2016.

2. French DD, Campbell RR, Sabharwal S, Nelson AL, Palacios PA, Gavin-Dreschnack D. Health care costs for patients with chronic spinal cord injury in the Veterans Health Administration. J Spinal Cord Med. 2007;30(5):477-481.

3. Silver J, Miller JH. Regeneration beyond the glial scar. Nat Rev Neurosci. 2004;5(2):146-156.

4. Bible E, Dell'Acqua F, Solanky B, et al. Non-invasive imaging of transplanted human neural stem cells and ECM scaffold remodeling in the stroke-damaged rat brain by (19)F- and diffusion-MRI. Biomaterials. 2012;33(10):2858-2871.

5. Ritfeld GJ, Rauck BM, Novosat TL, et al. The effect of a polyurethanebased reverse thermal gel on bone marrow stromal cell transplant survival and spinal cord repair. Biomaterials. 2014;35(6):1924-1931.

6. Ziemba AM, Gilbert RJ. Biomaterials for local, controlled drug delivery to the injured spinal cord. Front Pharmacol. 2017;8:245.

7. Luo J, Borgens R, Shi R. Polyethylene glycol improves function and reduces oxidative stress in synaptosomal preparations following spinal cord injury. J Neurotrauma. 2004;21(8):994-1007.

8. Wilems TS, Lu X, Kurosu YE, Khan Z, Lim HJ, Smith Callahan LA. Effects of free radical initiators on polyethylene glycol dimethacrylate hydrogel properties and biocompatibility. J Biomed Mater Res A. 2017;105(11):3059-3068.

9. Perale G, Rossi F, Sundstrom E, et al. Hydrogels in spinal cord injury repair strategies. ACS Chem Neurosci. 2011;2(7):336-345.

10. Boomer JA, Qualls MM, Inerowicz HD, et al. Cytoplasmic delivery of liposomal contents mediated by an acid-labile cholesterol-vinyl ether-PEG conjugate. Bioconjug Chem. 2009;20(1):47-59.

11. Kang CE, Tator CH, Shoichet MS. Poly(ethylene glycol) modification enhances penetration of fibroblast growth factor 2 to injured spinal cord tissue from an intrathecal delivery system. $J$ Control Release. 2010;144(1):25-31.

12. Zustiak SP, Leach JB. Hydrolytically degradable poly(ethylene glycol) hydrogel scaffolds with tunable degradation and mechanical properties. Biomacromolecules. 2010;11(5):1348-1357.

13. Soderquist RG, Milligan ED, Sloane EM, et al. PEGylation of brain-derived neurotrophic factor for preserved biological activity and enhanced spinal cord distribution. $J$ Biomed Mater Res A. 2009;91(3):719-729.

14. Zheng J, Smith Callahan LA, Hao J, et al. Strain-promoted crosslinking of PEG-based hydrogels via copper-free cycloaddition. $A C S$ Macro Lett. 2012;1(8):1071-1073.

15. Turecek PL, Bossard MJ, Schoetens F, Ivens IA. PEGylation of biopharmaceuticals: a review of chemistry and nonclinical safety information of approved drugs. J Pharm Sci. 2016;105(2):460-475.

16. Roberts MJ, Bentley MD, Harris JM. Chemistry for peptide and protein PEGylation. Adv Drug Deliv Rev. 2012;64:116-127.

17. Geckil H, Xu F, Zhang X, Moon S, Demirci U. Engineering hydrogels as extracellular matrix mimics. Nanomedicine (Lond). 2010;5(3):469-484.

18. Lin CC, Anseth KS. PEG hydrogels for the controlled release of biomolecules in regenerative medicine. Pharm Res. 2009;26(3):631-643.

19. Mahoney MJ, Anseth KS. Three-dimensional growth and function of neural tissue in degradable polyethylene glycol hydrogels. Biomaterials. 2006;27(10):2265-2274. 
20. Smith Callahan LA, Policastro GM, Bernard SL, Childers EP, Boettcher $\mathrm{R}$, Becker ML. Influence of discrete and continuous culture conditions on human mesenchymal stem cell lineage choice in RGD concentration gradient hydrogels. Biomacromolecules. 2013;14(9):3047-3054.

21. Williams CG, Malik AN, Kim TK, Manson PN, Elisseeff JH. Variable cytocompatibility of six cell lines with photoinitiators used for polymerizing hydrogels and cell encapsulation. Biomaterials. 2005;26(11):1211-1218.

22. Lin S, Sangaj N, Razafiarison T, Zhang C, Varghese S. Influence of physical properties of biomaterials on cellular behavior. Pharm Res. 2011;28(6):1422-1430.

23. Kim J, Kong YP, Niedzielski SM, Singh RK, Putnam AJ, Shikanov A. Characterization of the crosslinking kinetics of multi-arm poly(ethylene glycol) hydrogels formed via Michael-type addition. Soft matter. 2016;12(7):2076-2085.

24. Tan H, Marra KG. Injectable, biodegradable hydrogels for tissue engineering applications. Materials. 2010;3(3):1746-1767.

25. Song A, Rane AA, Christman KL. Antibacterial and cell-adhesive polypeptide and poly(ethylene glycol) hydrogel as a potential scaffold for wound healing. Acta Biomaterialia. 2012;8(1):41-50.

26. Hutanu D, Frishberg MD, Guo L, Darie CC. Recent applications of polyethylene glycols (PEGs) and PEG derivatives. Mod Chem Appl. 2014;2(2):1000132

27. Spencer KC, Sy JC, Ramadi KB, Graybiel AM, Langer R, Cima MJ. Characterization of mechanically matched hydrogel coatings to improve the biocompatibility of neural implants. Sci Rep. 2017;7(1):1952.

28. Bradbury EJ, Carter LM. Manipulating the glial scar: chondroitinase $\mathrm{ABC}$ as a therapy for spinal cord injury. Brain Res Bull. 2011;84(4):306-316.

29. Nazari-Robati M, Khajeh K, Aminian M, Mollania N, Golestani A. Enhancement of thermal stability of chondroitinase ABC I by sitedirected mutagenesis: an insight from Ramachandran plot. Biochim Biophys Acta. 2013;1834(2):479-486.

30. Shahaboddin ME, Khajeh K, Maleki M, Golestani A. Improvement of activity and stability of Chondroitinase $\mathrm{ABC}$ I by introducing an aromatic cluster at the surface of protein. Enzyme Microb Technol. 2017;105:38-44.

31. Brown JM, Xia J, Zhuang B, et al. A sulfated carbohydrate epitope inhibits axon regeneration after injury. Proc Natl Acad Sci USA. 2012;109(13):4768-4773.

32. Stephen DS. The biology of neurotrophins, signalling pathways, and functional peptide mimetics of neurotrophins and their receptors. CNS Neurol Disord Drug Targets. 2008;7(1):46-62.

33. O'Leary PD, Hughes RA. Design of potent peptide mimetics of brainderived neurotrophic factor. J Biol Chem. 2003;278(28):25738-25744.

34. Lang BT, Cregg JM, DePaul MA, et al. Modulation of the proteoglycan receptor PTPsigma promotes recovery after spinal cord injury. Nature. 2015;518(7539):404-408.

35. Mao Y, Tonkin RS, Nguyen T, et al. Systemic administration of connexin43 mimetic peptide improves functional recovery after traumatic spinal cord injury in adult rats. J Neurotrauma. 2017;34(3):707-719.

36. Ohtake Y, Park D, Abdul-Muneer PM, et al. The effect of systemic PTEN antagonist peptides on axon growth and functional recovery after spinal cord injury. Biomaterials. 2014;35(16):4610-4626.

37. Iwasaki M, Wilcox JT, Nishimura Y, et al. Synergistic effects of selfassembling peptide and neural stem/progenitor cells to promote tissue repair and forelimb functional recovery in cervical spinal cord injury. Biomaterials. 2014;35(9):2617-2629.

38. Zweckberger K, Ahuja CS, Liu Y, Wang J, Fehlings MG. Self-assembling peptides optimize the post-traumatic milieu and synergistically enhance the effects of neural stem cell therapy after cervical spinal cord injury. Acta Biomater. 2016;42:77-89.

39. Zustiak SP, Durbal R, Leach JB. Influence of cell-adhesive peptide ligands on poly(ethylene glycol) hydrogel physical, mechanical and transport properties. Acta Biomater. 2010;6(9):3404-3414.
40. Naghdi P, Tiraihi T, Ganji F, Darabi S, Taheri T, Kazemi H. Survival, proliferation and differentiation enhancement of neural stem cells cultured in three-dimensional polyethylene glycol-RGD hydrogel with tenascin. J Tissue Eng Regen Med. 2016;10(3):199-208.

41. Tashiro K, Sephel GC, Weeks B, et al. A synthetic peptide containing the IKVAV sequence from the A chain of laminin mediates cell attachment, migration, and neurite outgrowth. $J$ Biol Chem. 1989;264(27):16174-16182.

42. Silva GA, Czeisler C, Niece KL, et al. Selective differentiation of neural progenitor cells by high-epitope density nanofibers. Science. 2004;303(5662):1352-1355.

43. Li X, Liu X, Josey B, et al. Short laminin peptide for improved neural stem cell growth. Stem Cells Transl Med. 2014;3(5):662-670.

44. Adams DN, Kao EY, Hypolite CL, Distefano MD, Hu WS, Letourneau PC. Growth cones turn and migrate up an immobilized gradient of the laminin IKVAV peptide. J Neurobiol. 2005;62(1):134-147.

45. Fawcett JW. The extracellular matrix in plasticity and regeneration after CNS injury and neurodegenerative disease. Prog Brain Res. 2015;218:213-226.

46. Smith Callahan LA. The concentration game: differential effects of bioactive signaling in 2D and 3D culture. Neural Regen Res. 2016;11(1):66-68.

47. Lim HJ, Mosley MC, Kurosu Y, Smith Callahan LA. Concentration dependent survival and neural differentiation of murine embryonic stem cells cultured on polyethylene glycol dimethacrylate hydrogels possessing a continuous concentration gradient of $\mathrm{n}$-cadherin derived peptide His-Ala-Val-Asp-Lle. Acta Biomater. 2017;56:153-160.

48. Lim HJ, Khan Z, Wilems TS, et al. Human induced pluripotent stem cell derived neural stem cell survival and neural differentiation on polyethylene glycol dimethacrylate hydrogels containing a continuous concentration gradient of N-Cadherin derived peptide His-Ala-ValAsp-Ile. ACS Biomater Sci Eng. 2017;3(5):776-781.

49. Yang YH, Khan Z, Ma C, Lim HJ, Smith Callahan LA. Optimization of adhesive conditions for neural differentiation of murine embryonic stem cells using hydrogels functionalized with continuous Ile-Lys-ValAla-Val concentration gradients. Acta Biomater. 2015;21:55-62.

50. Mosley MC, Lim HJ, Chen J, et al. Neurite extension and neuronal differentiation of human induced pluripotent stem cell derived neural stem cells on polyethylene glycol hydrogels containing a continuous Young's Modulus gradient. J Biomed Mater Res A. 2017;105(3):824-833.

51. Ozawa H, Matsumoto T, Ohashi T, Sato M, Kokubun S. Comparison of spinal cord gray matter and white matter softness: measurement by pipette aspiration method. J Neurosurg. 2001;95(2 Suppl):221-224.

52. Russell LN, Lampe KJ. Oligodendrocyte precursor cell viability, proliferation, and morphology is dependent on mesh size and storage modulus in 3D Poly(ethylene glycol)-based hydrogels. ACS Biomater. Sci. Eng. 2017;3(12):3459-3468.

53. Yan Y, Li Y, Song L, Zeng C. Pluripotent stem cell expansion and neural differentiation in 3-D scaffolds of tunable Poisson's ratio. Acta Biomater. 2017;49:192-203.

54. Rammensee S, Kang MS, Georgiou K, Kumar S, Schaffer DV. Dynamics of mechanosensitive neural stem cell differentiation. Stem Cells. 2017;35(2):497-506.

55. Lourenco T, Paes de Faria J, Bippes CA, et al. Modulation of oligodendrocyte differentiation and maturation by combined biochemical and mechanical cues. Sci Rep. 2016;6:21563.

56. Russell LN, Lampe KJ. Engineering biomaterials to influence oligodendroglial growth, maturation, and myelin production. Cells Tissues Organs. 2016;202(1-2):85-101.

57. Happel RD, Smith KP, Naren Banik L, James Powers M, Hogan EL, Douglas Balentine J. Ca2+-accumulation in experimental spinal cord trauma. Brain Research. 1981;211(2):476-479.

58. Huff TB, Shi Y, Sun W, Wu W, Shi R, Cheng J-X. Real-time CARS imaging reveals a calpain-dependent pathway for paranodal myelin retraction during high-frequency stimulation. PLoS One. 2011;6(3):e17176. 
59. Nehrt A, Hamann K, Ouyang H, Shi R. Polyethylene glycol enhances axolemmal resealing following transection in cultured cells and in ex vivo spinal cord. J Neurotrauma. 2010;27(1):151-161.

60. Wang A, Zhang G, Xiaochen W, Zhang C, Tao S, Huo X. Combination of applied electric field and polyethylene glycol effectively enhance functional recovery in acute spinal cord injury of rats. Paper presented at: 2016 Asia-Pacific International Symposium on Electromagnetic Compatibility (APEMC); 17-21 May 2016, 2016.

61. Carballo-Molina OA, Velasco I. Hydrogels as scaffolds and delivery systems to enhance axonal regeneration after injuries. Front Cell Neurosci. 2015;9(13).

62. Censi R, Di Martino P, Vermonden T, Hennink WE. Hydrogels for protein delivery in tissue engineering. J Control Release. 2012;161(2):680-692.

63. Trimaille T, Pertici V, Gigmes D. Recent advances in synthetic polymer based hydrogels for spinal cord repair. Comptes Rendus Chimie. 2016;19(1):157-166.

64. Luo J, Borgens R, Shi R. Polyethylene glycol immediately repairs neuronal membranes and inhibits free radical production after acute spinal cord injury. J Neurochem. 2002;83(2):471-480.

65. Shi R. Polyethylene glycol repairs membrane damage and enhances functional recovery: a tissue engineering approach to spinal cord injury. Neurosci Bull. 2013;29(4):460-466.

66. Ren S, Liu Z-H, Wu Q, et al. Polyethylene glycol-induced motor recovery after total spinal transection in rats. CNS Neurosci Ther. 2017;23(8):680-685.

67. Liu Z, Ren S, Fu K, et al. Restoration of motor function after operative reconstruction of the acutely transected spinal cord in the canine model. Surgery. 2018;163(5):976-983.

68. Anderson MA, Burda JE, Ren Y, et al. Astrocyte scar formation aids central nervous system axon regeneration. Nature. 2016;532(7598):195-200.

69. Kim CY. PEG-assisted reconstruction of the cervical spinal cord in rats: effects on motor conduction at 1h. Spinal Cord 2016;54:910-912.

70. Estrada V, Brazda N, Schmitz C, et al. Long-lasting significant functional improvement in chronic severe spinal cord injury following scar resection and polyethylene glycol implantation. Neurobiol Dis. 2014;67:165-179.

71. Macaya D, Spector M. Injectable hydrogel materials for spinal cord regeneration: a review. Biomed Mater. 2012;7(1):012001.

72. Oda Y, Tani K, Isozaki A, et al. Effects of polyethylene glycol administration and bone marrow stromal cell transplantation therapy in spinal cord injury mice. J Vet Med Sci. 2014;76(3):415-421.

73. Huang Z, Filipovic Z, Mp N, et al. AC105 Increases extracellular magnesium delivery and reduces excitotoxic glutamate exposure within injured spinal cords in rats. J Neurotrauma. 2016;34(3):685-694.

74. Agnes EH, Ines M-L, Martin O. Biomaterials for revascularization and immunomodulation after spinal cord injury. Biomed Mater. 2018;13(4):044105.

75. Jain A, Kim YT, McKeon RJ, Bellamkonda RV. In situ gelling hydrogels for conformal repair of spinal cord defects, and local delivery of BDNF after spinal cord injury. Biomaterials. 2006;27(3):497-504.

76. Comolli N, Neuhuber B, Fischer I, Lowman A. In vitro analysis of PNIPAAm-PEG, a novel, injectable scaffold for spinal cord repair. Acta Biomater. 2009;5(4):1046-1055.

77. Cai L, Dewi RE, Heilshorn SC. Injectable hydrogels with in situ double network formation enhance retention of transplanted stem cells. $A d v$ Funct Mater. 2015;25(9):1344-1351.

78. Tyler JY, Xu XM, Cheng JX. Nanomedicine for treating spinal cord injury. Nanoscale. 2013;5(19):8821-8836.

79. Kim YT, Caldwell JM, Bellamkonda RV. Nanoparticle-mediated local delivery of methylprednisolone after spinal cord injury. Biomaterials. 2009;30(13):2582-2590.

80. Kang CE, Baumann MD, Tator $\mathrm{CH}$, Shoichet MS. Localized and sustained delivery of fibroblast growth factor-2 from a nanoparticlehydrogel composite for treatment of spinal cord injury. Cells Tissues Organs. 2013;197(1):55-63.
81. Hotta R, Cheng L, Graham HK, et al. Delivery of enteric neural progenitors with 5-HT4 agonist-loaded nanoparticles and thermosensitive hydrogel enhances cell proliferation and differentiation following transplantation in vivo. Biomaterials. 2016;88:1-11.

82. Veronese FM, Mero A. The impact of PEGylation on biological therapies. BioDrugs. 2008;22(5):315-329.

83. Gefen T, Vaya J, Khatib S, et al. The impact of PEGylation on protein immunogenicity. Int Immunopharmacol. 2013;15(2):254-259.

84. Ku S, Yan F, Wang Y, Sun Y, Yang N, Ye L. The blood-brain barrier penetration and distribution of PEGylated fluorescein-doped magnetic silica nanoparticles in rat brain. Biochem Biophys Res Commun. 2010;394(4):871-876.

85. Richter AW, Akerblom E. Antibodies against polyethylene glycol produce in animals by immunization with monomethoxy polyethylene glycol modified proteins. Int Arch Allergy Appl Immunol. 1983;70(2):124-131.

86. Wunderlich DA, Macdougall M, Mierz DV, et al. Generation and characterization of a monoclonal IgG antibody to polyethylene glycol. Hybridoma (Larchmt). 2007;26(3):168-172.

87. Shimizu T, Ichihara M, Yoshioka Y, Ishida T, Nakagawa S, Kiwada H. Intravenous administration of polyethylene glycol-coated (PEGylated) proteins and PEGylated adenovirus elicits an anti-PEG immunoglobulin M response. Biol Pharm Bull. 2012;35(8):1336-1342.

88. Swartzlander MD, Barnes CA, Blakney AK, Kaar JL, Kyriakides TR, Bryant SJ. Linking the foreign body response and protein adsorption to PEG-based hydrogels using proteomics. Biomaterials. 2015;41:26-36.

89. Lynn AD, Blakney AK, Kyriakides TR, Bryant SJ. Temporal progression of the host response to implanted poly(ethylene glycol)-based hydrogels. J Biomed Mater Res A. 2011;96(4):621-631.

90. Garay RP, El-Gewely R, Armstrong JK, Garratty G, Richette P. Antibodies against polyethylene glycol in healthy subjects and in patients treated with PEG-conjugated agents. Expert Opin Drug Deliv. 2012;9(11):1319-1323.

91. Mima Y, Hashimoto Y, Shimizu T, Kiwada H, Ishida T. Anti-PEG IgM Is a major contributor to the accelerated blood clearance of polyethylene glycol-conjugated protein. Molecular Pharmaceutics. 2015;12(7):2429-2435.

92. Yang Q, Lai SK. Anti-PEG immunity: emergence, characteristics, and unaddressed questions. Wiley Interdiscip Rev Nanomed Nanobiotechnol. 2015;7(5):655-677.

93. Ishida T, Wang X, Shimizu T, Nawata K, Kiwada H. PEGylated liposomes elicit an anti-PEG IgM response in a $\mathrm{T}$ cell-independent manner. J Control Release. 2007;122(3):349-355.

94. Shimizu T, Mima Y, Hashimoto Y, et al. Anti-PEG IgM and complement system are required for the association of second doses of PEGylated liposomes with splenic marginal zone B cells. Immunobiology. 2015;220(10):1151-1160.

95. Vos Q, Lees A, Wu ZQ, Snapper CM, Mond JJ. B-cell activation by T-cell-independent type 2 antigens as an integral part of the humoral immune response to pathogenic microorganisms. Immunological Reviews. 2003;176(1):154-170.

96. Verhoef JJ, Carpenter JF, Anchordoquy TJ, Schellekens H. Potential induction of anti-PEG antibodies and complement activation toward PEGylated therapeutics. Drug Discov Today. 2014;19(12):1945-1952.

97. Papastefanaki F, Jakovcevski I, Poulia N, et al. Intraspinal delivery of polyethylene glycol-coated gold nanoparticles promotes functional recovery after spinal cord injury. Mol Ther. 2015;23(6):993-1002.

98. Papa S, Ferrari R, De Paola M, et al. Polymeric nanoparticle system to target activated microglia/macrophages in spinal cord injury. J Control Release. 2014;174:15-26.

99. Jenkins SI, Weinberg D, al-Shakli AF, et al. "Stealth" nanoparticles evade neural immune cells but also evade major brain cell populations: implications for PEG-based neurotherapeutics. J Control Release. 2016;224:136-145.

100. Li J, Deng J, Yuan J, et al. Zonisamide-loaded triblock copolymer nanomicelles as a novel drug delivery system for the treatment of acute spinal cord injury. Int J Nanomedicine. 2017;12:2443-2456. 
101. Wu J, Jiang H, Bi Q, et al. Apamin-mediated actively targeted drug delivery for treatment of spinal cord injury: more than just a concept. Mol Pharm. 2014;11(9):3210-3222.

102. Li J, Mooney DJ. Designing hydrogels for controlled drug delivery. Nat Rev Mater. 2016;1(12):16071.

103. Lee K, Silva EA, Mooney DJ. Growth factor delivery-based tissue engineering: general approaches and a review of recent developments. $J$ R Soc Interface. 2011;8(55):153-170.

104. Burdick JA, Ward M, Liang E, Young MJ, Langer R. Stimulation of neurite outgrowth by neurotrophins delivered from degradable hydrogels. Biomaterials. 2006;27(3):452-459.

105. Kong L, Askes SHC, Bonnet S, Kros A, Campbell F. Temporal control of membrane fusion through photolabile PEGylation of liposome membranes. Angew Chem Int Ed Engl. 2016;55(4):1396-1400.

106. Lampe KJ, Kern DS, Mahoney MJ, Bjugstad KB. The administration of BDNF and GDNF to the brain via PLGA microparticles patterned within a degradable PEG-based hydrogel: protein distribution and the glial response. J Biomed Mater Res A. 2011;96A(3):595-607.

107. Lynam DA, Shahriari D, Wolf KJ, et al. Brain derived neurotrophic factor release from layer-by-layer coated agarose nerve guidance scaffolds. Acta Biomater. 2015;18:128-131.

108. Elliott Donaghue I, Shoichet MS. Controlled release of bioactive PDGF-AA from a hydrogel/nanoparticle composite. Acta Biomater. 2015;25:35-42.

109. Garbayo E, Ansorena E, Lanciego JL, Aymerich MS, Blanco-Prieto MJ. Sustained release of bioactive glycosylated glial cell-line derived neurotrophic factor from biodegradable polymeric microspheres. Eur J Pharm Biopharm. 2008;69(3):844-851.

110. Stanwick JC, Baumann MD, Shoichet MS. Enhanced neurotrophin-3 bioactivity and release from a nanoparticle-loaded composite hydrogel. J Control Release. 2012;160(3):666-675.

111. Hammer N, Brandl FP, Kirchhof S, Messmann V, Goepferich AM. Protein compatibility of selected cross-linking reactions for hydrogels. Macromol Biosci. 2015;15(3):405-413.
112. van de Wetering P, Metters AT, Schoenmakers RG, Hubbell JA. Poly(ethylene glycol) hydrogels formed by conjugate addition with controllable swelling, degradation, and release of pharmaceutically active proteins. J Control Release. 2005;102(3):619-627.

113. Lin C-C, Metters AT. Enhanced Protein Delivery from Photopolymerized Hydrogels Using a Pseudospecific Metal Chelating Ligand. Pharm Res. 2006;23(3):614.

114. Censi R, Vermonden T, van Steenbergen MJ, et al. Photopolymerized thermosensitive hydrogels for tailorable diffusion-controlled protein delivery. J Control Release. 2009;140(3):230-236.

115. Langer R, Tirrell DA. Designing materials for biology and medicine. Nature. 2004;428(6982):487-492.

116. Hong LTA, Kim YM, Park HH, et al. An injectable hydrogel enhances tissue repair after spinal cord injury by promoting extracellular matrix remodeling. Nat Commun. 2017;8(1):533.

117. Hejcl A, Lesny P, Pradny M, et al. Biocompatible hydrogels in spinal cord injury repair. Physiol Res. 2008;57(Suppl 3):S121-132.

118. Liu C, Huang Y, Pang M, et al. Tissue-engineered regeneration of completely transected spinal cord using induced neural stem cells and gelatin-electrospun poly (Lactide-Co-Glycolide)/Polyethylene glycol scaffolds. PLoS One. 2015;10(3):e0117709.

119. Chen BK, Madigan NN, Hakim JS, et al. GDNF Schwann cells in hydrogel scaffolds promote regional axon regeneration, remyelination and functional improvement after spinal cord transection in rats J Tissue Eng Regen Med. 2018;12(1):e398-e407.

120. Caron I, Rossi F, Papa S, et al. A new three dimensional biomimetic hydrogel to deliver factors secreted by human mesenchymal stem cells in spinal cord injury. Biomaterials. 2016;75:135-147.

121. Hakim JS, Esmaeili Rad M, Grahn PJ, et al. Positively charged oligo[Poly(Ethylene Glycol) Fumarate] scaffold implantation results in a permissive lesion environment after spinal cord injury in rat. Tissue Engineering Part A. 2015;21(13-14):2099-2114.
Journal of Experimental Pharmacology

\section{Publish your work in this journal}

The Journal of Experimental Pharmacology is an international, peerreviewed, open access journal publishing original research, reports, reviews and commentaries on all areas of laboratory and experimental pharmacology. The manuscript management system is completely online and includes a very quick and fair peer-review system.

\section{Dovepress}

Visit http://www.dovepress.com/testimonials.php to read real quotes from published authors. 